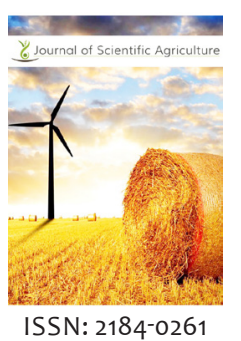

Received: March 28, 2019

Accepted: May 17, 2019

Published: May 20, 2019

Corresponding Author: Muhammad Shahid

shahid.css3322@gmail.com

\section{Resistance in Tribolium castaneum (Hbst.) against phosphine and deltamethrin}

\author{
Muhammad Shahid ${ }^{1,2}$, Farooq Ahmad², Mansoor-ul-Hasan², \\ Muhammad Sagheer', Muhammad Asad Saleem', Unsar Naeem-Ullah', \\ Muhammad Siddique', Mirza Abdul Qayyum', Furqan Ahmed', Abdur Rauf', \\ Rao Muhammad Shamriaz', Muhammad Javaid', Muhammad Hasnain', \\ Muhammad Ishtiaq'
}

'Department of entomology, Muhammad Nawaz Shareef University of Agriculture, Multan, Pakistan, ${ }^{2}$ Department of Entomology, University of Agriculture, Faisalabad, Pakistan

\begin{abstract}
The red flour beetle Tribolium castaneum (Hbst.) is the most destructive pest of the stored grains and responsible for causing the tremendous loss to stored grains depends upon the storage structures and conditions. It deteriorates the quality and quantity of the stored grains. The current study was carried out to monitor the level of resistance in red flour beetle against phosphine and deltamethrin. Six concentrations of phosphine $(0.006,0.007,0.008,0.009,0.01$ and $0.011 \mathrm{ppm})$ and deltamethrin $(0.01,0.02,0.03,0.04,0.05$ and $0.06 \mathrm{ppm})$ were used against this test insect. The mortality data of this insect against phosphine was recorded after 7, 14 and 21 days of treatment. The data regarding mortality $(\%)$ was recorded after 24,48 and 72 hours. The results showed that the maximum mortality of resistant and susceptible strain of T. castaneum against deltamethrin at $0.06 \%$ was $38.78 \%$ and $72.52 \%$ respectively. The maximum mortality of resistant and susceptible strain of T. castaneum against phosphine at $0.011 \mathrm{ppm}$ was $74.46 \%$ and $76.81 \%$ respectively. All the data showed that Tribolium castaneum was 4.86 times fold resistant against deltamethrin after 72 hours' time interval than over susceptible strains. The $\mathrm{LC}_{50}$ value showed that $\mathrm{T}$. castaneum was 0.75 times fold resistant against phosphine after 7 days' time interval than over susceptible strains.
\end{abstract}

KEYWORDS: Red flour beetle, Tribolium Castaneum, resistance, deltamethrin, phosphine

\section{INTRODUCTION}

The most important stored grain insect pest which is severely prompt the infestation in storage structures is Tribolium castaneum (Hbst.) [1]. The stored grain insect pests cause the major profitable losses like reduction of nutrients and grain losses [2]. Insect pests also cause the health hazards by the production of aflatoxic material like uric acid [3]. During favorable environment, the infestation rates of the insects are increase which makes the goods unpalatable for human consumption [4]. The insect pest like T. castaneum which feed in the internal side of the grains cause the quantity loss and damage the kernel of the grains [5]. The T. castaneum represents a serious threat to the farmers by causing the grain losses [6]. Emekci [7] observe that these species are well established in hot and humid environment which is suitable for their proper growth and development. In all the storage beetles, T. castaneum has ability to move from one gowdon to other and easily bring about the infestations in stored commodities [8]. Eggs are laying on the surface of the grains by the females which hatch and larvae enter into the kernels of the grains [9].

Lorini reported resistance in T. castaneum to deltamethrin [10,11]. Fumigation is also done by the application of Phosphine gas which is an important fumigant for the control of the stored products pest's in through of the world since 1930. It is used to protect the stored products pests. It is comparatively cheap, multipurpose and easy to apply. It is most toxic to those organisms which are aerobically respiring in the storage structures but nontoxic to metabolically dormant and anaerobic organisms [12]. The primary fumigant which is particularly used to protect the greater part of grains and wide diversity of other storage merchandise from insect pests is Phosphine [13,14]. Fumigation of Phosphine is an effective method to manage insect pests of stored product, but the repeated applications and injurious use of this resulted in development of resistant in

Copyright: (c) The authors. This article is open access and licensed under the terms of the Creative Commons Attribution License (http://creativecommons.org/licenses/by/4.0/) which permits unrestricted, use, distribution and reproduction in any medium, or format for any purpose, even commercially provided the work is properly cited. Attribution - You must give appropriate credit, provide a link to the license, and indicate if changes were made. 
populations [15]. Stored products pests develop the resistance against phosphine has become worldwide concern.

Therefore, the present research was conducted to evaluate the efficiencies of different concentrations of deltamethrin and phosphine for highest mortality and to examine that which concentrations of deltamethrin and phosphine shows more resistance against T. castaneum.

\section{MATERIAL AND METHODS}

\section{Collection and Rearing of T. castaneum}

The research trials were carried out in the Grain Research Training and Storage Management Cell (GRTSMC), Department of Entomology, University of Agriculture, Faisalabad during the year 2016-17. The material was comprised of T. castaneum deltamethrin, phosphine, filter paper, petri dishes, jars, camel hair brush, micropipette and desiccators chambers. Adults of T. castaneum was collected from Godown of the Punjab Food Department and grain market of District Muzaffargarh and was reared in the laboratory to develop homogenous population.

After collection, the insect populations were kept in the jars. The capacity of jars was $800 \mathrm{gm}$ in which insect populations was reared. The jars were sterilized at $60^{\circ} \mathrm{C}$ for $60-90$ minutes. The jars were filled with un-infested wheat flour diet for proper growth and development of studied insects. The jars were covered with muslin cloths to prevent escape and the entry of ants or other insects. Insect population was regularly checked to avoid from infestation. The jars were kept in incubator. The temperature of $30 \pm 2^{\circ} \mathrm{C}$ and R.H $70 \pm 5 \%$ was maintained in laboratory [16]. Each jar was filled with $200 \mathrm{~g}$ wheat grains and mixed with $20 \mathrm{~g}$ flour. About 100 beetles were added to each jar assuming 50 males and 50 females. Beetles were allowed for 3 days to oviposit in the medium. After 3 days, the insects was removed with the help of sieves using camel hair brushes from the media and was added to another set of sterilized jars filled with $200 \mathrm{~g}$ wheat grains and $20 \mathrm{~g}$ flour for further infestation for the purpose of fresh culture development. The flour containing eggs of the test insect were placed in other jar to get different larval stages of the test insects and the fresh adults. It was take approximately 28 days for reaching to $6^{\text {th }}$ instars larvae and 39 days to become adult. Homogenous population of equal size and age was sieved out which later on was used for bioassay studies.

\section{Preparation of Test Chemicals}

The deltamethrin (Guardian 1.5 EC) was diluted in ethanol to obtain $0.01,0.02,0.03,0.04,0.05$ and $0.06 \mathrm{ppm}$ solution to be tested against the test insects. These concentrations were prepared for experimental purpose by talking $0.66 \mathrm{ml}, 1.33 \mathrm{ml}$, $2 \mathrm{ml}, 2.66,3.33 \mathrm{ml}$ and $4 \mathrm{ml}$ deltamethrin added with 99.34, 98.67, 98, 97.34, 96.67 and $96 \mathrm{ml}$ ethanol respectively.

Test insects were initially be exposed to a discriminating dose of phosphine in accordance with the method recommended by FAO. Phosphine was generated from aluminum phosphide tablets. Fumigation chamber was used for the application of phosphine against the test insects. Within the desiccators, insects were confined in $50 \mathrm{cc}$ beakers closed with nylon mesh. Six concentrations $(0.006,0.007,0.008,0.009,0.01$ and $0.011 \mathrm{ppm}$ ) of phosphine were used. The mortality data of phosphine concentrations were recorded after 7 days, 14 days and 21 days. Micro syringe was used for the injection of phosphine gas into desiccators through a rubber septum fitted to a socket in the desiccators' lid. The desiccators were placed in the lab line walk in environment chamber at $25 \mathrm{DC}$ and $65 \%$ R.H for $20 \mathrm{~h}$ after which observations on mortality was made. Resistant strains were tested at a series of doses to record their "resistance factor" all the tests were triplicate for obtaining accuracy.

The response of deltamethrin at different doses for different time intervals was checked against T. castaneum. Circular plastic petri dishes $(150 \times 25 \mathrm{~mm})$ were used as testing arena. A filter paper (Fisher Sci., Pittsburg, Penn.) was placed in the bottom of each petri dish. Ethanol solution of $0.01,0.02,0.03$, 0.04, 0.05 and 0.06 ppm deltamethrin were applied separately to the filter papers in the dishes through micropipette. The solvent was completely evaporated by the opening of the petri dishes for an hour. Thirty adults of T. castaneum were released in each treatment including control for up to 72 hours. The petri dishes were covered with lid to avoid the escape of the test insect. Six concentrations $(0.006,0.007,0.008,0.009,0.01$ and $0.011 \mathrm{ppm}$ ) of phosphine were used. The data regarding percent mortality was recorded after 7 days, 14 days and 21 days. All the treatments including control were replicated thrice. Though, the mortality of the test insect in each concentration were recorded after 24, 48 and 72 hours, an overall mean percent mortality in each concentration in the mentioned three time intervals were analyzed with Analysis of Variance (ANOVA), Tuckey HSD and Probit analysis. The resistance factor was calculated by using the following formula:

$$
\text { Resistant Factor }=\frac{\mathrm{LC}_{50} \text { of susceptible strain }}{\mathrm{LC}_{50} \text { of resistances train }}
$$

\section{RESULTS}

The present study was carried out to determine the resistance level in T. castaneum against deltamethrin and phosphine in different strains. The test insect T. castaneum was exposed to six concentrations of deltamethrin $0.01,0.02,0.03,0.04$, 0.05 and $0.06 \mathrm{ppm}$ and six concentrations of phosphine 0.006 , $0.007,0.008,0.009,0.01$ and $0.011 \mathrm{ppm}$. The effects of these concentrations were recorded after 24, 48 and 72 hours for deltamethrin and after 7, 14 and 21 days for phosphine. The mean percentage mortality of adults at various concentrations of deltamethrin in Muzaffargarh field and laboratory $(0.01$, $0.02,0.03,0.04,0.05$ and $0.06 \mathrm{ppm}$ ) is given in the (Figure. 1) which reveals that the mortality of the adult insects was directly related to increase of concentrations. When the concentrations of insecticides were increased then the mortality of the test insects was increased. The results showed that at 
the higher concentrations of insecticides, mortality of the insects was increased. The highest mortality was recorded at $0.06 \%$ concentration was $38.78 \%$ of adult T. castaneum in field condition and $72.62 \%$ in laboratory condition. The mean mortality of the insects in field at other concentrations $(0.01$, $0.02,0.03,0.04$ and $0.05 \mathrm{ppm})$ was $11.78,18.25,26.23,22.43$, and $30.8 \%$ respectively and in laboratory was $15.48,30.56,50$, 58.33 and $66.27 \%$ respectively.

The mean percentage mortality of adults of T. castaneum at various concentrations of phosphine $(0.006,0.007,0.008,0.009$, 0.01 and $0.011 \mathrm{ppm}$ ) is given in the (Figure. 2) which reveals that the mortality of the adult insects was directly related to increase of concentrations. The maximum mean mortality was recorded at $0.011 \mathrm{ppm}$ concentration was $74.46 \%$ of adult $T$. castaneum in field condition and $36.81 \%$ in lab condition. The mean mortality of the insects at other concentrations $(0.006$,
0.007, 0.008, 0.009 and $0.01 \mathrm{ppm}$ ) was 9.36, 29.78, 48.93, 58.29 and $63.4 \%$ respectively and in laboratory was $2.55,11.06,19.57$, 16.59 and $25.32 \%$ respectively.

The results regarding mean mortality (\%) of adults of T. castaneum in field conditions after various time intervals $(24,48$, and 72 hours) by the application of deltamethrin in the given above (Table 1). The data shows that the maximum mean mortality of the adult insect $(30.22 \%)$ was observed after 72 hours' time interval by the application of deltamethrin followed by $18.44 \%$ and $25.47 \%$ after 24 and 48 hours' time intervals respectively. While at the same time interval the application of deltamethrin in laboratory condition shows that the maximum mean mortality of the adult insect $(52.78 \%)$ was observed after 72 hours' time interval by the application of deltamethrin followed by $44.05 \%$ and $49.80 \%$ after 24 and 48 hours' time intervals respectively. In both strains the data shows that when

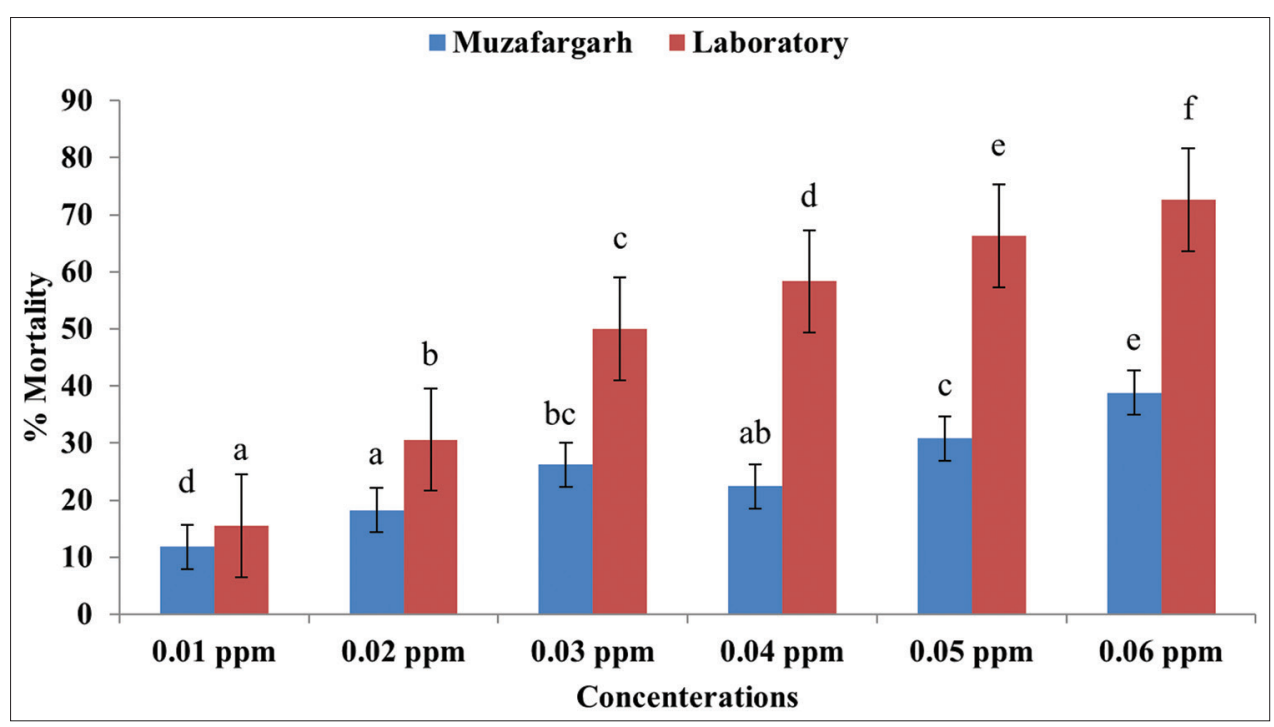

Figure 1: Comparison of mean values data regarding $\%$ mortality of Muzaffargarh and laboratory strain of $T$. castaneum at different concentrations of deltamethrin

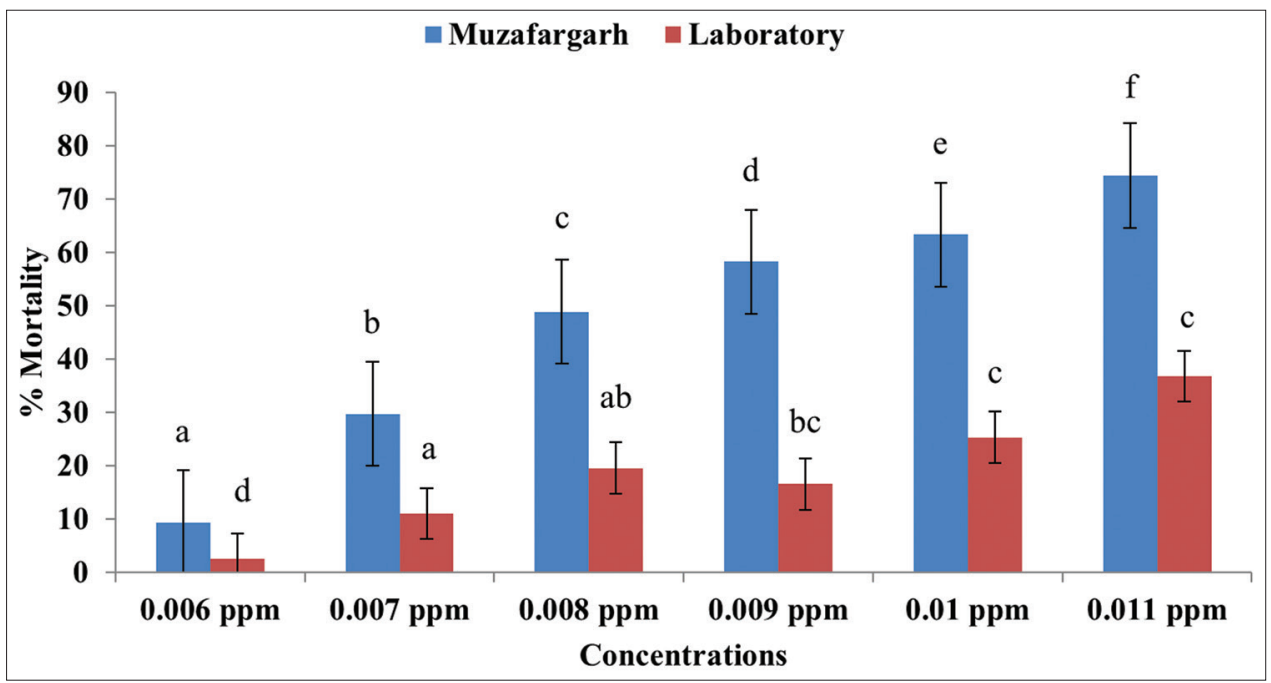

Figure 2: Comparison of mean values data regarding \% mortality of Muzaffargarh and laboratory strain of $T$. castaneum at different concentrations of Phosphine 
the exposure times of the insecticides was increased then the mortality of the insects was also increased.

The results regarding mean mortality (\%) of adults of T. castaneum in field conditions after various time intervals (7, 14 and 21 days) by the application of phosphine in the given above (Table 2). The data shows that the maximum mean mortality of the adult insect $(52.34 \%)$ was observed after 21 days' time interval by the application of phosphine followed by $42.98 \%$ and $46.81 \%$ after 7 and 14 days' time intervals respectively. While in laboratory conditions the data shows that the maximum mean mortality of the adult insect (24.68\%) was observed after 21 day time interval by the application of phosphine followed by $12.34 \%$ and $19.57 \%$ after 7 and 14days time intervals respectively. In both strains the data shows that when the exposure times of the phosphine was increased then the mortality of the test insects was also increased.

The log probit analysis was used to evaluate the $\mathrm{LC}_{50}$ values at the various concentrations $(0.01,0.02,0.03,0.04,0.05$ and $0.06 \mathrm{ppm}$ ) of deltamethrin after 24 hours' time interval in the above given (Table 3) two strains of T. castaneum were collected, one from District Muzaffargarh and the other from laboratory strain which was susceptible and considered as a standard. The

Table 1: Comparison of mean values of the data regarding $\%$ mortality of Muzaffargarh and Laboratory strain of T. castaneum after different times intervals after treatment various concentrations of deltamethrin

\begin{tabular}{lcc}
\hline Exposure Time & Mortality \pm SE in field & Mortality \pm SE in laboratory \\
\hline 24 hours & $18.44 \pm 2.69^{\mathrm{a}}$ & $44.05 \pm 5.33^{\mathrm{b}}$ \\
48 hours & $25.47 \pm 2.17^{\mathrm{b}}$ & $49.80 \pm 4.86^{\mathrm{a}}$ \\
72 hours & $30.22 \pm 2.05^{\mathrm{c}}$ & $52.78 \pm 4.69^{\mathrm{a}}$ \\
\hline
\end{tabular}

Table 2: Comparison of mean values of the data regarding \% mortality of Muzaffargarh and laboratory strain Population of $T$. castaneum after different times intervals after treatment various concentrations of Phosphine

\begin{tabular}{lcc}
\hline Exposure Time & Mortality $\pm S E$ in field & Mortality \pm SE in laboratory \\
\hline 7 days & $42.98 \pm 5.97^{\mathrm{a}}$ & $12.34 \pm 3.26^{\mathrm{a}}$ \\
14 days & $46.81 \pm 5.23^{\mathrm{b}}$ & $19.57 \pm 2.69^{\mathrm{b}}$ \\
21 days & $52.34 \pm 4.83^{\mathrm{c}}$ & $24.68 \pm 2.55^{\mathrm{c}}$ \\
\hline
\end{tabular}

resistance factor (R.F) was calculated to compare the two strains of T. castaneum. The data showed that the T. castaneum was 2.28, 3.63 and 4.86 times fold resistant against deltamethrin after 24, 48 and 72 hours' time interval than over laboratory susceptible strains. While phosphine showed $0.75,0.684$ and 0.60 times fold resistant after 7,14 and 21 days' time interval than over laboratory susceptible strains.

\section{DISCUSSION}

Research trials was carried out in the Grain Research Training and Storage Management Cell (GRTSMC), Department of Entomology, University of Agriculture, Faisalabad during the year 2016-17. In this experiment, there were firstly checked the mortality of the stored grain insect pest. Different concentrations of insecticides were used against this insect to evaluate that the effective concentration of the both deltamethrin and phosphine which caused the highest mortality of the stored grain insect pest. Among these concentrations, there was indicated that which concentration was the most effective for the controlling of this stored grain insect pest. The main purpose of this experiment was monitoring of the resistance in T. castaneum against deltamethrin and phosphine. Resistance is the avoidance of biotic and abiotic factors. In most of the stored grain insect pests, resistance was developed against both the deltamethrin and phosphine.

The main reason for the development of resistance was due to the repeated applications of the same mode of action of insecticides. There were two strains of T. castaneum taken, one from field and the other from laboratory which was kept as a standard. T. castaneum strains were collected from various places of District Muzaffargarh. The field strains were found to be $11.78,18.25,26.23,22.43,30.80$ and 38.78 times more resistant as compared to the laboratory susceptible strain. These findings of our experiment were similar to those of Ahmad et al. [17] who reported that both strains of $T$. castaneum exhibited the diverse level of resistance against deltamethrin. In the case of field population, the highest mortality was occurred at $0.06 \%$ concentration was $41.82 \%$. The results were almost similar. But due to some uncertain situations the results were incompatible with the previous results was due to different geographical

Table 3: Probit analysis for the comparative evaluation of level of resistance in Muzaffargarh and Laboratory strain of red flour beetle, $T$. castaneum against deltamethrin after 24,48,72 hours and phosphine used after 7,14 and 21 days exposure time period

\begin{tabular}{llccc}
\hline Locality & Strains (LGB) & Exposure Time & LC $_{50}$ & 95\% Fiducial limit \\
\hline Muzaffargarh & MGS & 24 hours & 0.0867475 & $0.0697341-0.128988$ \\
Laboratory & LS & 24 hours & 0.0379401 & $0.0345798-0.0414776$ \\
Muzaffargarh & MGS & 48 hours & 0.116414 & $0.0764431-0.331931$ \\
Laboratory & LS & 48 hours & 0.0320686 & $0.0283490-0.0357373$ \\
Muzaffargarh & MGS & 72 hours & 0.140826 & $0.0772148-1.33238$ \\
Laboratory & LS & 72 hours & 0.0289678 & $0.0250784-0.0326361$ \\
Muzaffargarh & MGS & 7 days & 0.0091021 & $0.0088172-0.0093856$ \\
Laboratory & LS & 7 days & 0.0121359 & $0.0114192-0.0134125$ \\
Muzaffargarh & MGS & 14 days & 0.0087934 & $0.0084504-0.0091285$ \\
Laboratory & LS & 14 days & 0.0128387 & $0.0116188-0.0154874$ \\
Muzaffargarh & MGS & 21 days & 0.0082237 & 0.75 \\
Laboratory & LS & 21 days & 0.0136293 & $0.0078336-0.0085696$ \\
\hline
\end{tabular}

$\mathrm{LGB}=$ lesser grain borer, MGS=Muzaffargarh Gowdon strain, LS=Laboratory Strain 
distribution of the species, Micro-environment of the laboratory and climate change effect the population buildup of the species.

Both the populations of T. castaneum were exposed with phosphine fumigation to check the level of resistance against different phosphine concentrations 0.006, 0.007, 0.008, $0.009,0.01$ and $0.011 \mathrm{ppm}$. The data showed that the field population was gave the highest mortality as compared to the laboratory population. Hence, the laboratory population was more resistant as compared to the field population against different concentrations of phosphine. Those findings of our experiment were similar to Pimentel et al. [18] who evaluated the phosphine resistance in 12 populations of T. castaneum. The highest mortality of the test insect was done at the highest concentration $0.011 \%$ was $75 \%$ in laboratory population.

\section{CONCLUSION}

The cross resistance was observed mostly related to these compounds in T. castaneum which is the notorious pest of the stored products pest. The results of the current experiment were further showed that, the resistance levels ranging from 4.86 times fold against deltamethrin in T. castaneum respectively. The level of resistance against phosphine was 0.60 times fold against phosphine in T. castaneum. This leads to the conclusion that maximum resistance exists in T. castaneum against deltamethrin followed by the phosphine was minimum resistant.

\section{ACKNOWLEDGEMENT}

Authors are thankful to Grain Research Training and Storage Management Cell (GRTSMC), Department of Entomology, University of Agriculture Faisalabad, Pakistan for providing research facilities.

\section{REFERENCES}

1. Jood, S, Kapoor AC, Singh. Effect of infestation and storage on lipids of cereals, Journal of Agriculture and Food Chemistry, 1996; 44:209-212.

2. Girish GK, Kumar A, Jain SK. Part VI: assessment of the quality loss in wheat damaged by Trogoderma granarium Everts during storage. Bulletin of Grain Technology, 1975;13:26-32.
3. Swaminathan M. Effect of insect infestation on weight loss, hygienic condition, acceptability and nutritive value of Food grains. The Indian Journal of Nutrition and Dietetics, 1977;14:205-206.

4. Vassanacharoen P, Pttanapo W, Lucke W, Vearasilp S. Control of Sitophilus oryzae (L.) by radio frequency heat treatment as alternative phytosanitary processing in milled rice. Journal of Plant Diseases and Protection, 2008;115(1):45

5. Campbell A, Sinha RN. Damage of wheat by feeding of some stored product beetles. Journal of Economic Entomologist, 1976;69:11-13.

6. Chimoya IA, Abdullahi G. Species compositions and relative abundance of insect pests associated with some stored cereals grains in selected markets of Maiduguri metropolitan. The Journal of American Science, 2011;7:355-358.

7. Emekci MS, Navarrow E. Donhaye, Rinder, M, Azrieli A. Respiration of Rhyzopertha dominica (F.) at reduced oxygen concentration. Journal of Stored Products Research, 2004;40:27-38.

8. Khan SM, Marwat AA. Effects of bakain (Melia azadarach) and Ak (Calatropis procera) against Lesser grain borer Rhyzopertha dominica (F.). Journal of Research in Science Teaching, 2004;15:319-324.

9. Ozkaya H, Ozkaya B, Colakoglu AS. Technological properties of variety of soft and hard bread wheat infested by Rhyzopertha dominica (F.) and Tribolium castaneum du val. Journal of Food, Agriculture and Environment, 2009; 7:166-179.

10. Lorini I. Application of pest management integrated in stored inventories. In: Embrapa-CNPT (Ed.). Proof of Protection of Stockpiled Officers. Embrapa, Passo Fundo. 1993;117-126.

11. Lorini I, Schneider S. Stockpiled Pests: Search Results Embrapa-CNPT, Passo Fundo. 1994.

12. Chaudhry MQ. A review of the mechanisms involved in the action of phosphine is an Insecticide and phosphine resistance in stored product insects. Pesticide Science, 1997;49:213-228.

13. Benhalima H, Chaudhry MQ. Mills KA, Price NR. Phosphine resistance in stored-product insects collected from various grain storage facilities in Morocco Journal of Stored Product Research, 2004; 40:241-249.

14. Collins PJ, Daglish GJ, Pavic H, Kopittke RA. Response of mixed age cultures of phosphine resistant and susceptible strains of lesser grain borer, Rhyzopertha dominica, to phosphine at a range of concentrations and exposure periods. Journal of Stored Product Research, 2005;41:373-385.

15. Lorini I, Collins PJ, Daglish GJ, Nayak MK, Pavic H. Detection and characterization of strong resistance to phosphine in Brazilian Rhyzopertha dominica (F.) (Coleoptera: Bostrichidae). Pest Management Science, 2007;63:358-364.

16. Nawaz K, Shahid M, Ahmad F, Sagheer M, Saleem MA, NaeemUllah U, Sadique M. Assessment of resistant varieties of maize against Tribolium castaneum (Herbst)(Coleoptera: Tenebrionidae) in laboratory conditions. Journal of Scientific Agriculture, 2019;3:6-8.

17. Ahmad A, Ahmed M, Nourullah, Ali GM, Abbas M, Arif S. Monitoring of resistance against phosphine in stored grain insect pests in Sindh. Middle-East Journal of Scientific Research, 2013;16 (11):1501-1507.

18. Pimentel MAG, Faroni LRDA, Tótola MR, Guedes RNC. Phosphine resistance, respiration rate and fitness consequences in stored product insects. Pest Management Science, 2007;63:876-881. 